Review

\title{
The determination of plastic material and the optimal irrigation characteristics for an agricultural surface - model description
}

\author{
Victor Tita ${ }^{1}$, Nicolae Bold ${ }^{2}$, Valentina Constanta Tudor ${ }^{1}$, Alina Marcuta ${ }^{*}$ and Marcuta Liviu ${ }^{1 *}$ \\ 1 University of Agricultural Sciences and Veterinary Medicine Bucharest, Faculty of Management and Rural \\ Development, Romania; victortita@yahoo.com; valentina tudor@yahoo.com; alinamarcuta@yahoo.com \\ 2 University of Pitești, Faculty of Sciences, Physics Education and Computer Science; \\ bold nicolae@yahoo.com \\ * Correspondence: liviumarcuta@yahoo.com; alinamarcuta@yahoo.com
}

\begin{abstract}
Water management and soil pollution are hot issues in modern agriculture. While more production of food is required, this quantity has to be obtained using the minimum level of resources and the maximum amortization of assets. Moreover, studies show that in Europe, $30 \%$ of water consumption is for agriculture, which has a strong influence not only on the amount of water consumed, but also on its quality due to pollution caused by chemical fertilizers, pesticides and other pollutants used in this sector. Therefore, a major concern is related to the use of water, its efficient consumption, which requires optimal irrigation systems both in terms of water transport and distribution. In this context, but also in the context of a turbid environmental debate, the most important facts in agriculture are the protection of the environment on a long range of time. In order to obtain good results for an irrigation system, in this paper we will present a model for calculating the best suited material for a given geographical area and the optimal water content for irrigation.
\end{abstract}

Keywords: optimality, irrigation, drip, plastic, agriculture

\section{Introduction}

Drip irrigation is a method that can achieve efficient management of water resources and can also contribute to the protection of the environment, an aspect that is increasingly sensitive today [4, 13]. Irrigation is the most important factor contributing to the increase of agricultural production, hence its importance for agriculture [1]. To the same extent, however, account must be taken of the materials used, which are mostly plastics, whose influence on the environment must be treated responsibly, given that plastics are indispensable materials in all sectors of the economy, but their use must be controlled given the impact they can have on the environment $[5,14]$. There is a growing concern of all decision-makers regarding environmental issues resulting from their production and use, and this is demonstrated by documents developed and accepted at European and global level $[15,20]$. One of the sectors in which different plastics are used is the agricultural sector $[9,10]$. In agriculture, the use of plastic materials, in addition to the use of chemical fertilizers, pesticides, etc. of practicing intensive and semi-intensive systems have made negative contributions on the environment $[2,16]$.

Strategies to reduce the impact that the use of plastics has on the environment is correct and necessary, and finding solutions and promoting them does nothing but increase performance [12], but at the same time ensure food security by achieving larger and more stable productions $[6,8]$.

This paper takes into consideration the development of a drip-irrigation system with materials choice based on external data related to soil and climate. Further, we will determine the water necessary for the soil. Previous research has been made on determining the optimal water necessary in the literature $[5,10,11]$ and by the authors and we will present the model in the next sections. We 
will extend it then by adding useful facts regarding the material used to create the drip irrigation system pipes based on environmental factors. Finally, we will make some simulations in order to validate the closeness to reality of the model.

\section{Materials and Methods}

Firstly, we will present the irrigation model. The model is based on the literature $[7,18]$ calculations. Thus, the amount of the soil water is calculated accordingly to equation (1):

$$
S W C_{T}=S W C_{Y}+E P+I-E T P-I D(1)
$$

where:

- $\quad \mathrm{SWC}_{\mathrm{T}}$ is the soil water content from today;

- SWCY is the soil water content from yesterday;

- EP is the effective precipitation from yesterday;

- I is the irrigation level from yesterday;

- ETP is the evapotranspiration;

- DP is the internal drain.

The model has the next definitions:

- $S W C:\{1,2, \ldots, n\} \rightarrow R, S W C i=$ the soil water content from area $\mathrm{i}$;

- $\mathrm{MIN}:\{1,2, \ldots, \mathrm{n}\} \rightarrow \mathrm{R}, \mathrm{MINi}=$ the minimum limit of soil water in area $\mathrm{i}$, or the maximum allowable deficit;

- $\operatorname{MAX}:\{1,2, \ldots, \mathrm{n}\} \rightarrow \mathrm{R}, \mathrm{MAX} \mathrm{i}=$ the maximum limit of soil water in area $\mathrm{i}$, which varies depending on the soil type from $83 \mathrm{~mm}$ for sandy soils to $200 \mathrm{~mm}$ for clay;

- $\operatorname{DEP}:\{1,2, \ldots, \mathrm{n}\} \rightarrow \mathrm{R}, \mathrm{DEPi}=$ the depth of the roots.

\section{Results}

Next, we will present data related to the main plastic used for pipes used in a drip irrigation system. These can be seen in Table 1 (calculated by [3] and [19]).

Table 1. Proprieties for the usual materials used in agriculture as pipes for drip irrigation system.

\begin{tabular}{|c|c|c|c|c|c|c|}
\hline \multirow{3}{*}{ Material } & \multicolumn{2}{|c|}{$\begin{array}{c}\text { Operating } \\
\text { temperature }\end{array}$} & \multirow{3}{*}{ UV resistance } & \multirow{3}{*}{$\begin{array}{c}\begin{array}{c}\text { Water } \\
\text { absorption }\end{array} \\
\%\end{array}$} & \multirow{3}{*}{$\begin{array}{c}\begin{array}{c}\text { Impact } \\
\text { strength }\end{array} \\
\mathrm{MPa}\end{array}$} & \multirow{3}{*}{$\begin{array}{c}\text { Food } \\
\text { compatibility }\end{array}$} \\
\hline & Min & $\operatorname{Max}$ & & & & \\
\hline & C & C & & & & \\
\hline EVA & 0 & 55 & Very good / 3 & 0 & 26.54 & Yes \\
\hline LDPE & 0 & 80 & Moderate / 2 & 0.10 & 9.65 & Yes \\
\hline $\mathrm{PP}$ & -10 & 130 & Very good / 3 & slight & 37.23 & Yes \\
\hline PVC & 0 & 50 & Moderate / 2 & $0.15-0.30$ & 7.500 & Yes \\
\hline HDPE & -50 & 80 & Poor / 1 & 0.10 & 51.71 & Yes \\
\hline LLDPE & 0 & 65 & Very good / 3 & 0.10 & $7.93-45.51$ & Yes \\
\hline Bioplastic & 0 & 110 & - & - & - & Yes \\
\hline
\end{tabular}

After the determination of the possible usage materials for pipes, we will describe the model that helps at the optimization of the drip irrigation system based on the used material. In this matter, the relation that characterizes the choice of the most suitable material for a drip irrigation system is shown at equation (2).

$$
I_{M}=\left(T_{A \min }-T_{M \min }\right)+\left(T_{M \max }-T_{A \max }\right)+U V_{C}+1 / W_{A}
$$

TA stands for the temperatures of the area. The determination of the best material can be made using an optimization technique, such a genetic algorithm. The algorithm components are: 
- The genes, formed of four genes which consist in each characteristic of the material: the first gene is the minimum operating temperature, the second gene is the maximum operating temperature, the third gene is the classification based on UV resistance and the fourth one is the water absorption coefficient;

- $\quad$ The chromosome consists in the material used within the irrigation system;

- $\quad$ The fitness value consists in the application of the equation (2) for each chromosome. The fitness value will be a maximum one, which means the chromosome with the maximum fitness function will be selected.

Finally, after the appliance of the genetic algorithm, the resulted chromosome with the highest fitness value will be selected and this chromosome will be the material with the best suited genes for the given conditions (minimum and maximum temperature of the area and UV radiation level, classified in three classes: low, medium and high). The implementation results will be shown in a further study.

In an integrated vision, the model and the development of the future application would consist in the form presented in Figure 1.

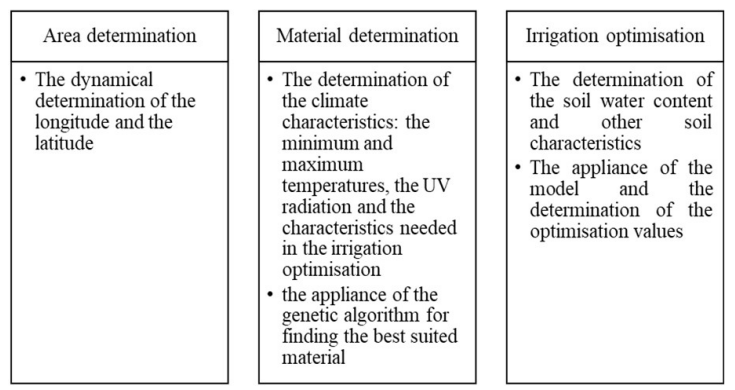

Figure 1. Model description for the given issue.

For a given $S W C i, M I N i$ and $M A X i, i=1,2, . . n$, the model verifies the next relation:

- $\quad \mathrm{MINi} \times \mathrm{DEPi} \leq \mathrm{SWCi} \leq \mathrm{MAXi} \times \mathrm{DEPi}$, which means that soil water content is lower or equal than the minimum limit of soil water, $\mathrm{i}=1,2, \ldots, \mathrm{n}$;

- $\quad$ the algorithm outputs the difference between MAXi $\times$ DEPi and SWCi (MAXi - SWCi) and alerts the start of irrigation when $\mathrm{SWCi} \leq \mathrm{MINi} \times \mathrm{DEP}_{\mathrm{i}}$.

\section{Discussion}

We have created a System Dynamic based model for the integrated environment described above.

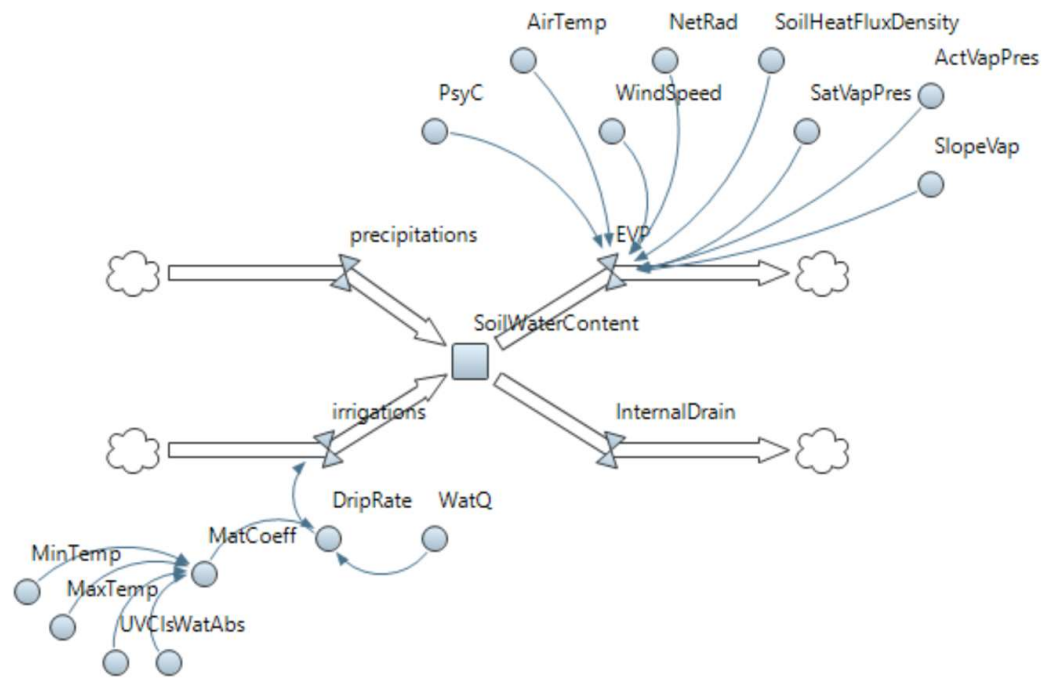

Figure 2. SD model for the optimized drip irrigation system.

We can observe that the level variable SoilWaterContent is positively influenced by the precipitation 
and irrigation levels, while the negative influence comes from the evapotranspiration and the internal drain within the soil. The irrigation is influenced by the index formed from the fitness value of the best chromosome obtained in the genetic algorithm and the evapotranspiration is calculated according to Penman-Monteith relation [17], presented in equation 3.

$$
E V P_{0}=\left[0.408 \times \Delta x\left(R_{n}-G\right)+\gamma \times 900 /(T+273) \times u_{2} x\left(e_{s}-e_{0}\right)\right] /\left[\Delta+\gamma+\left(1+0.34 x u_{2}\right)\right](3)
$$

where:

- $\Delta$ is the slope vapor pressure curve

- $\quad R_{n}$ is the net radiation

- $\quad G$ is the soil heat flux density

- $\quad T$ is the air temperature

- $\quad \mathrm{e}_{\mathrm{s}}$ is the saturation vapor pressure

- $\quad \mathrm{e}_{0}$ is the actual vapor pressure

- $\quad \mathrm{u}_{2}$ is the wind speed

- $\quad \gamma$ is the psychrometric content

The results for the irrigation surface can be observed in Figure 3.

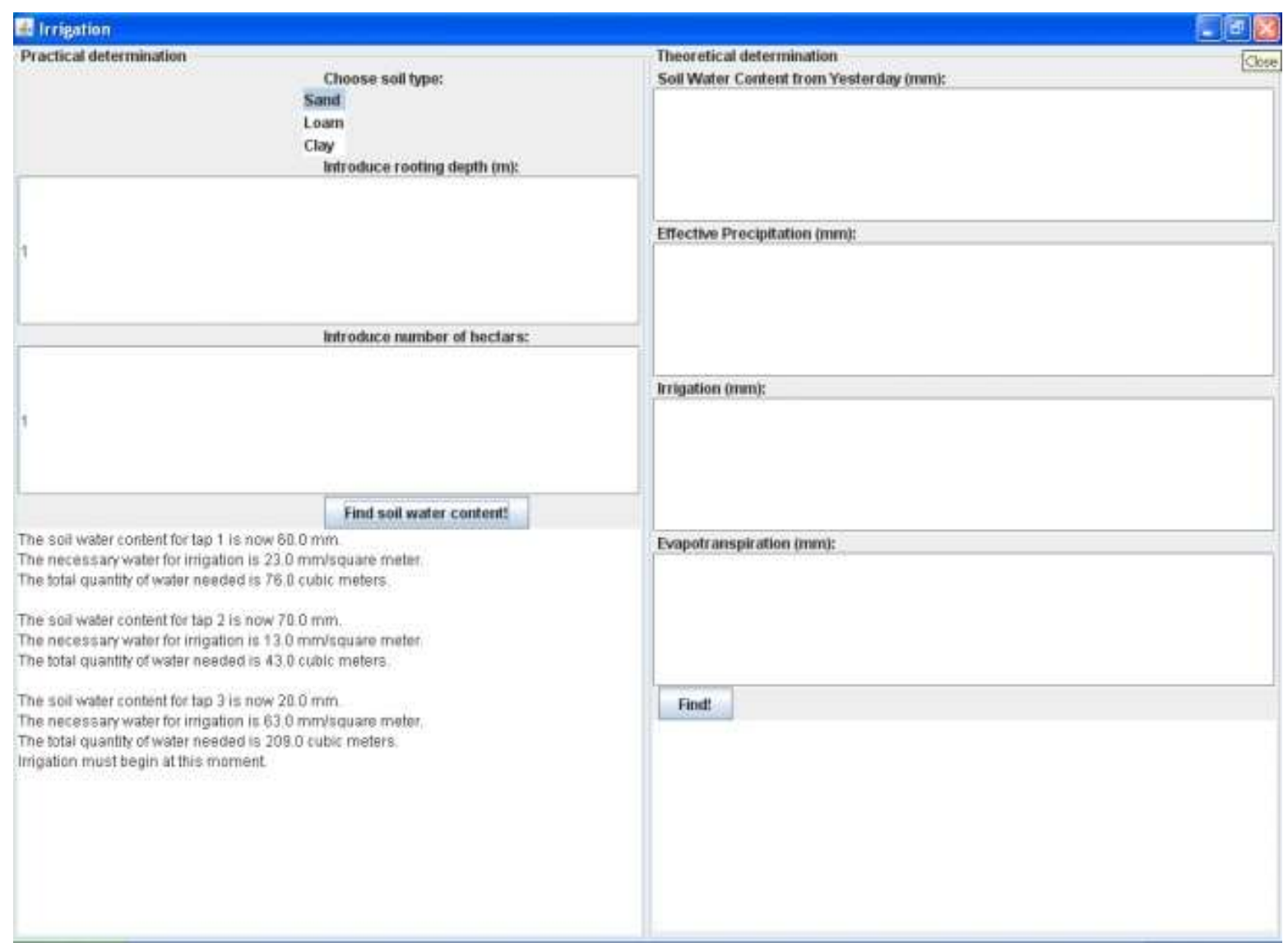

Figure 3. Implementation of the optimization of water consumption issue within the model.

As we can observe, the implementation shows the necessary amount of water, and the level of soil water content needed for an optimal irrigation based on the soil type. Also, the level is checked by the theoretical determination shown in equation (1).

\section{Conclusions}


The study conducted on the determination of plastic material and the optimal irrigation characteristics for an agricultural surface - model description highlights that the optimal resources can be dynamically allocated in agriculture based on key parameters related to the materials used and the climate of the area. The next steps would consist in the implementation of the genetic algorithm in a user-friendly manner and further study in order to stabilize the model from a scientific point of view6. Patents

\section{References}

1. Capra A., Scicolone B., Recycling of poor quality urban wastewater by drip irrigation systems, Journal of Cleaner Production 15 (2007) 1529-1534

2. Castellano S., Scarascia Mugnozza G., Russo G., Briassoulis D., Mistriotis A., Hemming S., Waaijenberg D., Plastic Nets in Agriculture a General Review of Types and Applications, American Society of Agricultural and Biological Engineers, St. Josep, Mighihan, www.asabe.org,

3. Eker, B., Alkan, M., Eker, A. A., Developing Flat Drip Irrigation Pipes Using Bioplastic Materials. Advances in Materials Science and Applications, 2014, 3, 62-74. 10.5963/AMSA0302003

4. Dioudis Paschalis, Filintas Agathos, Papadopoulos Aristotelis, Sakellariou-Makrantonaki Maria, The influence of different drip irrigation layout designs on sugar beet yield and their contribution to environmental sustainability, Fresenius Environmental Bulletin, Volume 19 - No 5. 2010

5. Feng Jun, Hussain Hafiz Athar, Hussain Saddam, Shi Chao, Cholidah Linna, Men Shengan, Ke Jianhong, Wang Longchang, Optimum Water and Fertilizer Management for Better Growth and Resource Use Efficiency of Rapeseed in Rainy and Drought Seasons, Suitable Agronomic Techniques for Sustainable Agriculture), 2020, 12(2), 703

6. Gordon J. Line, Finalyson C. Max, Falkenmark Malin, Managing water in agriculture for food production and other ecosystem services, Agricultural Water Management, Volume 97, Issue 4, April 2010, Pages 512-519

7. Harishankar, S., Kumar, R. S., Vignesh, S. K. P., U., Viveknath, T., Solar Powered Smart Irrigation System, Advance in Electronic and Electric Engineering, 4(4), 2014, 341-346

8. Ingman Mark, Santelmann Mary V., Tilt Bryan, Agricultural water conservation in china: plastic mulch and traditional irrigation, Ecosystem Health and Sustainability Volume 1, 2015 - Issue 4

9. Maraveas Chrysanthos, The Sustainability of Plastic Nets in Agriculture, Suitable Agronomic Techniques for Sustainable Agriculture, 2020, 12(9), 3625

10. Rani, M. U., Kamalesh, S., Web Based Service to Monitor Automatic Irrigation System for the Agriculture Field Using Sensors, 2014 International Conference on Advances in Electrical Engineering (ICAEE), Vellore, 2014, 1-5. doi: 10.1109/ICAEE.2014.6838569

11. Rasin, Z., Hamzah, H., Shahrieel, M., Aras, M., Application and Evaluation of High Power Zigbee Based Wireless Sensor Network in Water Irrigation Control Monitoring System, 2009 IEEE Symposium on Industrial Electronics \& Applications, Kuala Lumpur, 2009, 548-551, doi: 10.1109/ISIEA.2009.5356380

12. Scarascia-Mugnozza Giacomo, Sica Carmela, Russo Giovanni, Plastic materials in european agriculture: actual use and perspectives, Journal of Agriculture Engineering, Vol. 42 No. 3 (2011)

13. Thompson T.L., Pang Huan-cheng, Li Yu-yi, The Potential Contribution of Subsurface Drip Irrigation to Water-Saving Agriculture in the Western USA, Agricultural Sciences in China

Volume 8, Issue 7, July 2009, Pages 850-854

14. Tudor Valentina Constanta, Marin Ancuta, Zamfir Vasca Diana, Micu Marius Mihai, Smedescu Dragos Ion, 2018, The Influence of the Plastic Bags on the Environment, Materiale Plastice (Mater. Plast.), Year 2018, Volume 55, Issue 4, 595-599

15. Tudor Valentina Constanta, Smedescu Dragos Ion, Fintineru Gina, Fintineru Alexandru, Marcuta Alina, Iova Andrei Radu, 2019, Plasticulture: Diffusion of Plastic Materials in the Agricultural Sector, Materiale Plastice (Mater. Plast.), Year 2019, Volume 56, Issue 4, 730-734, ISSN CD -ROM : 2537-5741 ISSN-L 0025-5289

16. Vox Giuliano, Loisi Rosa Viviana, Blanco Ileana, Mugnozza Giacomo Scarascia, Schettini Evelia, Mapping of agriculture plastic waste, Agriculture and Agricultural Science Procedia 8 (2016 ) 583-591 
17. Zotarelli, L., Dukes, M. D., Romero, C. C., Migliaccio, K. W., Morgan, K. T., Step by Step Calculation of the Penman-Monteith Evapotranspiration (FAO-56 Method), 2015, Publication \#AE459

18. British Columbia Ministry of Agriculture, Food and Fishery, Sprinkler Irrigation Scheduling using a Water Budget Method, Water Conservation Factsheet, 2015

19. Plastic Properties Table. Available online: https://www.curbellplastics.com/Research-Solutions/PlasticProperties

20. COM, A European strategy for plastics in a circular economy, SWD, 2018 